Pacific Journal of Mathematics

INTERPOLATION BY ANALYTIC FUNCTIONS 


\title{
INTERPOLATION BY ANALYTIC FUNCTIONS
}

\author{
ARne Stray
}

\begin{abstract}
It is shown that interpolation problems for $R(X), A(X)$ and $H^{\circ}\left(X^{\circ}\right)$ are local problems whenever $X$ is a compact plane set.
\end{abstract}

Introduction and notation. Let $X$ be compact plane set, $X^{\circ}$ its interior and $\partial X=X \backslash X^{\circ}$ its boundary.

$H^{\infty}\left(X^{0}\right)$ denotes all bounded complex-valued analytic functions on $X^{0} . \quad A(X)$ is all continuous functions on $X$ which are analytic in $X^{0}$. $R(X)$ denotes the uniform closure on $X$ of the rational functions with poles outside $X$.

A subset $E$ of $X$ is an interpolation set for $A(X)$ if $A(X) \backslash E$ (the restrictions to $E$ of the functions in $A(X)$ ) equals the space $C(E)$ of all continuous complex-valued functions on $E$.

$E$ is called a peak set for $A(X)$ if there exists $f \in A(X)$ such that $f=1$ on $E$ and $|f(x)|<1$ if $x \in X \backslash E$.

A peak interpolation set for $A(X)$ is a set $E$ which has both these properties. Peak and interpolation sets for $R(X)$ are defined in the same way.

A sequence $S=\left\{z_{n}\right\}$ of distinct points is called an interpolating sequence for $H^{\infty}\left(X^{0}\right)$ if for any bounded sequence $\left\{w_{n}\right\}$ of complex numbers there exists $f \in H^{\infty}\left(X^{0}\right)$ such that $f\left(z_{n}\right)=w_{n}$ for each $n$. (For more about interpolating sequences see Ch. 10 in [3].)

If $F$ is a subset of the complex plane we give it (as a toplogical space) the topology induced from $C . C_{b}(F)$ is the Banach space of all bounded continuous complex-valued functions on $F$. We also consider $H^{\infty}\left(X^{0}\right), R(X)$ and $A(X)$ as Banachspaces with the usual sup norm.

Let us mention two other Banach-spaces of analytic functions which has not been much studied yet, but which may be useful in characterizing interpolation sets for $R(X)$ and $A(X)$ among other things.

$H R(X)$ denotes all functions on $X^{0}$ which are pointwise limits on $X^{0}$ of bounded sequences in $R(X)$. For each $f \in H R(X)$ we define

$$
\|f\|_{H R}=\inf \left\{\sup _{n}\left\|f_{n}\right\|:\left\{f_{n}\right\} \subset R(X), f_{n} \longrightarrow f \text { pointwise on } X^{0}\right\} \text {. }
$$

With this norm $H R(X)$ clearly is a Banach space. In the same way we define $H A(X)$ corresponding to $A(X)$ and it is also a Banach space with the norm \|\|$_{H A}$. Very recently A. M. Davie has shown that the norm \|\|$_{H A}$ is the same as sup norm on $X^{0}$ and the same is proved for \|\|$_{H R}$ if almost every point of $\partial X$ (w.r.t. area) is a peak point for $R(X)$. We shall not need these interesting results 
here. (See [1] for his results.) Some results about $H R(X)$ can be found in [2].

If $f$ is a complex-valued function defined on a set $F$ and $S \subset F$ is a subset we define $\|f\|_{S}$ as $\sup \{|f(z)|: z \in S\}$.

A typical problem we shall study in this paper is the following:

Let $S$ be a sequence in $X^{0}$. What local conditions on $S$ are sufcient to conclude that $S$ is an interpolating sequence for $H^{\infty}\left(X^{\circ}\right)$ ?

An obvious necessary condition is that $S \cap \Delta_{z}$ is an interpolating sequence for $H^{\infty}\left(X^{0}\right)$ whenever $\Delta_{z}$ is an open disc centered at $z$ for which $\Delta_{z} \cap S \neq \varnothing$.

Suppose that the following weaker condition is satisfied:

$\left(^{*}\right)$ : For every $z \in \bar{S}$ (the closure of $S$ ) there exists $\delta_{z}>0$ such that $S \cap \Delta_{z}$ is an interpolating sequence for $H^{\infty}\left(\Delta_{z} \cap X^{0}\right)$ where $\Delta_{z}=$ $\left\{w:|w-z|<\delta^{z}\right\}$.

We shall then by definition say that $S$ admits local $H^{\infty}$-interpolation w.r.t. $X^{0}$.

Our main result is the following:

THEOREM 1. Let $X$ be a compact set with nonempty interior $X^{0}$. $A$ sequence $S$ in $X^{0}$ is an interpolating sequence for $H^{\infty}\left(X^{0}\right)$ if and only if $S$ admits local $H^{\infty}$-interpolation w.r.t. $X^{0}$.

Some time after Theorem 1 was proved we learnt about a result of J. Rainwater which has some connection with Theorem 1. If in the definition of local $H^{\infty}$-interpolation the condition $(*)$ had been replaced by the other necessary condition for interpolation mentioned above Theorem 1 would be a somewhat weaker result.

We want to point out this weaker result is easy to deduce from J. Rainwaters paper. (See [4].) We also want to point out that a theorem of E. L. Stout on interpolating sequences in multiply connected domains in an easy consequence of Theorem 1. (See [5].)

Interpolating sequences can clearly also be defined for $H R(X)$ and $H A(X)$. It should also be clear what is meant by saying that a sequence $S \subset X^{0}$ admits local $H R$-interpolation (or $H A$-interpolation) w.r.t. $X$.

It will follow from our proof that Theorem 1 also holds for $H R(X)$ and $H A(X)$. We shall give some reasons for this at the end of the proof.

Lemma 1. Let $X$ be as in Theorem 1 and $z_{0} \in \partial X$. Let $0<r_{1}<$ $r_{2}$ and define $0_{1}=\left\{w:\left|w-z_{0}\right|<r_{1}\right\}$ and $0_{2}=\left\{w:\left|w-z_{0}\right|>r_{2}\right\}$. Suppose there exists $z_{1} \in C \backslash X$ such that $r_{2}>\left|z_{1}-z_{0}\right|>r_{1}$

Let $S_{i}$ be an interpolating sequence for $H^{\infty}\left(X^{0} \cap 0_{i}\right)$ for $i=1,2$. 
Suppose $\bar{S}_{i} \subset 0_{i}$ for $i=1,2$.

Then $S=S_{1} \cup S_{2}$ is an interpolating sequence for $H^{\infty}\left(X^{0}\right)$.

Proof. Put $\Gamma_{i}=\partial 0_{i}$ for $i=1,2$.

Then $\operatorname{dist} \cdot\left(S, \Gamma_{i}\right)>0$.

Assume $h \in H^{\infty}\left(X^{\circ} \cap 0_{1}\right)$. Extend it to $C$ by defining $h(z)=0$ if $z \notin X^{0} \cap 0_{1}$.

Let $\delta>0$ be given. Then cover $C$ by open $\operatorname{discs} \Delta_{n}=\Delta\left(z_{n}, \delta\right)$ (of radius $\delta$ and centered at $z_{n}$ ) and choose continuously differentiable functions $g_{n}$ supported on $\Delta_{n}$ as in the scheme for approximation described on page 210 in [2].

Let $T_{g_{n}}$ be the integraloperator on $L^{\infty}(d x d y)$ defined by

$$
\begin{aligned}
T_{g_{n}}(f)(w) & =\frac{1}{\pi} \iint \frac{f(w)-f(z)}{w-z} \frac{\partial g_{n}}{\partial \bar{z}} d x d y \\
& =f(w) \cdot g_{n}(w)+\frac{1}{\pi} \iint \frac{f(z)}{z-w} \frac{\partial g_{n}}{\partial \bar{z}} d x d y
\end{aligned}
$$

We mention that $T_{g_{n}}(f)$ is analytic outside the support of $g_{n}$ and wherever $f$ is and that $T_{g_{n}}(f)$ is continuous wherever $f$ is.

Also $f-T_{g n}(f)$ is analytic in the interior of the set where $g_{n}$ attains the value 1. (See on p. 28-29 in [2] for more details.)

Put $h_{n}=T_{g n}(h)$. We are only interested in those $n$ for which $\bar{J}_{n} \cap \Gamma_{1} \cap X \neq \varnothing$. Assume this happens if and only if $1 \leqq n \leqq N$.

Then $h-\sum_{1}^{N} h_{n}=h-T_{\left(\Sigma_{1}^{N} g_{n}\right)}(h)$ is analytic near $\Gamma_{1} \cap X$ since $\sum_{1}^{N} g_{1}$ equals 1 near $\Gamma_{1} \cap X$.

Now there exist functions $\left\{H_{n}\right\}_{n=1}^{N}$ analytic outside a compact subset of $D_{n}=\left\{w:\left|w-z_{n}\right|<2 \delta\right\} \mid 0_{1}$ such that $h_{n}-H_{n}$ has a triple zero in the Taylor expansion at infinity and in our situation we can obtain $\left\|H_{n}\right\| \leqq c_{1}\|h\|$ where $c_{1}$ is an absolute constant. (See Theorem 7.4 on p. 213 in [2] and the proof of it.)

Now one has to observe two important facts.

(a) If $B$ is a subset of $C$ and $\operatorname{dist}\left(B, \Gamma_{1} \cap X\right)>0$ and $\varepsilon>0$ one can choose $\delta$ depending only on $\varepsilon$ and $\operatorname{dist}\left(B, \Gamma_{1} \cap X\right)$ so small that the sum $f_{\delta}=h-\sum_{1}^{N}\left(h_{n}-H_{n}\right)$ satisfies

$$
\left\|h-f_{\delta}\right\|_{B} \leqq \varepsilon\|h\| \text {. }
$$

(b) The functions $H_{n}$ can be chosen such that its singularities lies on a fixed compact subset of $D_{n}$ independent of $h$.

In fact one can find two functions $F_{n, 1}$ and $F_{n, 2}$ analytic outside a compact subset of $D_{n}$ such that $\left\|F_{n, 1}\right\|+\left\|F_{n, 2}\right\| \leqq 20$ and $H_{n}=$ $\lambda_{n, 1}(h) F_{n, 1}+\lambda_{n, 2}(h) F_{n, 2}$. (See lemma 6.3 on page 209 in [2].)

Here $\lambda_{n, k}(h)$ is a complex number and we have

$$
\left|\lambda_{n, k}(h)\right| \leqq c_{2}\|h\| \quad \text { for } k=1,2,
$$


where $c_{2}$ in our situation is an absolute constant. If $F_{n, k}$ is constructed as in the mentioned lemma in [2]. We also mention that the maps $h \rightarrow \lambda_{n, k}(h)$ are linear.

(Some details indicating how this can be done, can be found in the proof of Lemma 3.1 in [4].)

Given $\varepsilon>0$ we first choose $\delta$ so small that

$$
\left\|h-f_{i}\right\|_{s}<\frac{\varepsilon\|h\|}{4}
$$

whenever $h$ is as above. The choose rational functions $r_{n, k}$ with poles only at $z_{1}$ such that

$$
\sum_{n=1}^{\mathrm{V}}\left(\left\|F_{n, 1}-r_{n, 1}\right\|_{0_{1} \cup 0_{2}}+\left\|F_{n, 2}-r_{n, 2}\right\|_{0_{1} \cup 0_{2}}\right)<\frac{\varepsilon}{4 c_{2}} .
$$

Now define $A_{1}: H^{\infty}\left(X^{0} \cap 0_{1}\right) \rightarrow H^{\infty}\left(X^{0}\right)$ by

$$
A_{1}(h)=\left[h-\sum_{1}^{v}\left(h_{n}-\left(\lambda_{n, 1}(h) r_{n, 1}+\lambda_{n, 2}(h) r_{n, 2}\right)\right)\right] \mid X^{0} .
$$

From (1), (2), (3) and (4) we deduce that tions $r_{n, l}$.

(i) $\left\|A_{1}(h)\right\| \leqq c_{4}\|h\|$ where $c_{4}$ depends only on the rational func-

(ii) $\left\|A_{1}(h)-h\right\|_{S} \leqq \varepsilon\|h\| / 4+\varepsilon\|h\| / 4=\varepsilon\|h\| / 2$.

In addition we also mention that $A_{1}$ is linear but this fact will not be needed.

In exactly the same way we define a map $A_{2}: H^{\infty}\left(X^{0} \cap 0_{2}\right) \rightarrow H^{\infty}\left(X^{0}\right)$.

Suppose now $f \in C_{b}(S)$. By the open mapping theorem applied to the restriction $H^{\infty}\left(0_{i} \cap X^{0}\right) \rightarrow C_{b}\left(S_{i}\right)$ for $i=1,2$, there exists a constrat $M$ independent of $f$ and functions $h_{i} \in H^{\infty}\left(0_{i} \cap X^{0}\right)$ such that

$$
\left\|h_{i}\right\| \leqq M\|f\| \text { and } h_{i}=f \text { on } S_{i} \text { for } i=1,2 \text {. }
$$

Put $h_{i}=0$ outside $0_{i} \cap X^{0}$ and define $g=A_{1}\left(h_{1}\right)+A_{2}\left(h_{2}\right)$.

Then $g \in H^{\infty}\left(X^{0}\right),\|g\| \leqq 2 c_{4} M\|f\|$ and $\|f-g\|_{S}=\| A_{1}\left(h_{1}\right)-h_{1}+$ $A_{2}\left(h_{2}\right)-h_{2}\left\|_{S} \leqq \varepsilon M\right\| f\|\leqq 1 / 2\| f \|$ if we choose $\varepsilon \leqq 1 / 2 M$.

Put $g_{1}=g$ and assume $g_{1}, \cdots, g_{n}$ constructed such that

$$
\left\|g_{k}\right\| \leqq 2^{-k+2} c_{4} M\|f\| \text { for } 1 \leqq k \leqq n
$$

and

$$
\left\|f-\sum_{1}^{n} g_{j}\right\|_{S} \leqq \frac{\|f\|}{2^{n}}
$$

By the approximation technique above one easily find $g_{n+1} \in H^{\infty}\left(X^{0}\right)$ such that $\left\|g_{n+1}\right\| \leqq 2^{-n-1} c_{4} M\|f\|$ and 


$$
\left\|f-\sum_{1}^{n+1} g_{j}\right\|_{S} \leqq \frac{\|f\|}{2^{n+1}} .
$$

By induction the series $\sum_{1}^{\infty} g_{n} \in H^{\infty}\left(X^{0}\right)$ interpolates $f$ on $S$.

LemMA 2. Let $S$ be a sequence in $X^{0}$ with no clusterpoints in $X^{0}$. Assume there exist $n$ points $z_{1}, \cdots, z_{n}$ and numbers $r_{k}>s_{k}>t_{k}$ for $1 \leqq k \leqq n$ such that the open discs $\left\{\Delta\left(z_{k}, t_{k}\right)\right\}_{k=1}^{n}$ cover $\bar{S}$.

Assume also that $(\boldsymbol{C} \backslash X) \cap\left\{w: r_{k}>\left|w-z_{k}\right|>s_{k}\right\}$ and $(\boldsymbol{C} \backslash X) \cap\{w:$ $\left.\left|s_{k}>\right| w-z_{k} \mid>t_{k}\right\}$ are nonempty for each $k$. If for each $\left.k,\right\lrcorner\left(z_{k}, r_{k}\right) \cap S$ is an interpolating sequence for $H^{\infty}\left(X^{0}\right)$ then also $S i s$.

Proof. We can assume $n \geqq 2$ and by induction the lemma to be true if $n$ is replaced by $n-1$.

Put $S_{1}=S \cap \Delta\left(z_{n}, t_{n}\right)$.

By hypothesis $S_{2}=S \cap\left(\bigcup_{1}^{n-1} \Delta\left(z_{k}, s_{k}\right)\right)$ is an interpolating sequence for $H^{\infty}\left(X^{0}\right)$ and given $f \in C(S)$ we can find $h_{1} \in H^{\infty}\left(X^{0}\right)$ such that $h_{1}=$ $f$ on $S_{2}$.

The choose $h_{2} \in H\left(X^{0}\right)$ equal to $f-h_{1}$ on $\Delta\left(z_{n}, r_{n}\right)$.

By Lemma 1 we can find $h_{3}$ in $H^{\infty}\left(X^{0}\right)$ such that $h_{3}=1$ on $S_{1}$ and $h_{3}=0$ on $S_{2} \backslash 4\left(z_{n}, s_{n}\right)$.

Then $h_{1}+h_{2} h_{3}=f$ on $S$.

Proof of Theorem 1. We have to show that the local condition implies that $S$ is an interpolating sequence.

$S$ has no clusterpoints in $X^{0}$ and for each $z \in(\partial X) \cap \bar{S}$ we can find $r_{z}>0$ and such that $\Delta\left(z, r_{z}\right) \cap S$ is an interpolating sequence for $H^{\infty}\left(X_{z}^{0}\right)$ where $X_{z}^{0}=\left\{w:|w-z|<2 r_{z}\right\} \cap X^{0}$. By Lemma $1 S \cap \Delta\left(z, r_{z}\right)$ is an interpolating sequence for $H^{\infty}\left(X^{0}\right)$.

Since $z \in \partial X$ we can choose $s_{z}>t_{z}>0$ such that $(C \backslash X) \cap\left\{w: r_{z}>\right.$ $\left.|w-z|>s_{z}\right\}$ and $(C \backslash X) \cap\left\{w: s_{z}>|w-z|>t_{z}\right\}$ are nonempty.

Since $\bar{S} \cap(\partial X)$ is compact we can obtain the hypothesis of Lemma 2 for a set $S^{\prime} \subset S$ such that $S \backslash S^{\prime}$ is finite.

But if $S^{\prime}$ is an interpolating sequence for $H^{\infty}\left(X^{0}\right)$ then clearly also $S$ is.

REMARK. To prove Theorem 1 in case $H=H R(X)$ one must modify the arguments slightly in the proof of Lemma 1 . We use the notation from that lemma.

Given $f \in C(S)$ one finds $h_{i} \in H R\left(\overline{0}_{i} \cap X\right)$ equal to $f$ on $S_{i}$ such that $\left\|h_{i}\right\|_{H R} \leqq M\|f\|$ where $M$ is a constant independent of $S$ found by using the open mapping theorem.

Then we find a sequence $\left\{g_{n}^{i}\right\}_{n=1}^{\infty} \subset C\left(S^{2}\right)$ analytic in a neighbourhood 
of $X \cap \overline{0}_{i}$ (depending on $n$ ) such that $\sup _{n}\left\|g_{n}^{i}\right\| \leqq 2 M\|f\|$ and such that $g_{n}^{i} \rightarrow h_{i}$ pointwise on the interior of $X \cap \overline{0}_{i}$. $\quad\left(S^{2}\right.$ denotes the extend complex plane with the usual topology.) We can also assume $g_{n}^{i}$ converges in the $w^{*}$-topology of $L^{\infty}(d x d y)$ to a function $\widetilde{h}_{i}$ equal to $h_{i}$ on $0_{i} \cap X^{0}$ such that $\left\|\widetilde{h}_{i}\right\|_{\infty} \leqq 2 M\|f\|$.

We can assume $\tilde{h}_{i}=0$ outside $\overline{0}_{i}$.

Then it is easy to see that $\sum_{i=1}^{2} A_{i}\left(\widetilde{h}_{i}\right)$ will approximate $f$ well on $S$ and that $A_{i}\left(g_{n}^{i}\right) \mid X$ belongs to $R(X)$ for all $n$ and that $A_{i}\left(g_{n}^{i}\right) \rightarrow$ $A_{i}\left(\widetilde{h}_{i}\right)$ pointwise on $X^{0}$. Also $\left\|A_{i}\left(\widetilde{h}_{i}\right)\right\|_{H R} \leqq k \cdot M\|f\| \cdot \quad(k$ is independent of $f$.)

With these remarks Lemma 1 also applies for $H R(X)$. It is clear that similar modiffications give Lemma 1 also for $H A(X)$.

But then the rest of the proof of Theorem 1 including the proof of Lemma 2 applies almost directly.

Corollary 1. Let $X$ be a compact plane set and $E_{a}$ closed subset.

Then $E$ is an interpolation set for $R(X)$ if and only if for each $z \in E$ there exists a closed disc $N_{z}=\left\{w:|w-z| \leqq r_{z}\right\}$ such that $E \cap$ $N_{z}$ is an interpolation set for $R\left(X \cap N_{z}\right)$.

Proof. Clearly $E_{z}=E \cap\{w:|w-z| \leqq z / 2\}$ is an interpolation set for $R\left(X \cap N_{z}\right)$.

The approximation technique used in the proof of Lemma 1 shows that $E_{z}$ then is an interpolation for $R(X)$.

But then the corollary follows from Rainwaters result.

REMARK. A similar corollary also clearly holds for $A(X)$.

Finally we state a theorem for $R(X)$ which is not difficult to prove. Perhaps it makes the space $H R(X)$ a little more attractive.

THEOREM 3. Let $S$ be a closed subset of a compact plane set $X$. Suppose that

(i) $S \cap \partial X$ is a peak interpolation set for $R(X)$

(ii) $S \cap X^{0}$ is an interpolating sequence for $H R(X)$.

Then $R(X) \mid S=C(S)$.

One proves Theorem 3 by showing that for every $f \in C(S)$ there exists $g \in R(X)$ such that

$$
\|f-g\|_{s} \leqq \frac{1}{2}\|f\| \text { and }\|g\| \leqq M\|f\|
$$

where $M$ is independent of $f$. This is sufficient by the approximation 
argument at the end of the proof of Lemma 1.

First choose $f_{1} \in R(X)$ such that $f_{1}=f$ on $S \cap \partial K$ and $\left\|f_{1}\right\| \leqq\|f\|$. Interpolate then $f-f_{1}$ on $S \cap X^{0}$ by $f_{2} \in H R(X)$ such that $\left\|f_{2}\right\|_{H R} \leqq$ $M_{1}\|f\|$ where $M_{1}$ is independent of $f$.

If $\varepsilon>0$ choose an open set $V_{\varepsilon} \supset S \cap \partial X$ such that $\left|f_{2}\right|<\varepsilon$ on $S \cap X^{\circ} \cap V_{\varepsilon}$.

Choose also $f_{3} \in R(X)$ such that ||$f_{3} \mid \leqq 2, f_{3}=0$ on $S \cap \partial X$ and $\left|1-f_{3}\right|<\varepsilon$ on $X \backslash V_{\varepsilon}$ and $f_{4} \in R(X)$ such that $\left|f_{4}(z)-f_{2}(z)\right| \leqq \varepsilon$ for all $z \in S$ where $\left|f_{3}(z)\right| \geqq \varepsilon$ and such that $\left\|f_{4}\right\| \leqq 2\left\|f_{2}\right\|_{H R} \leqq 2 M_{1}\|f\|$.

Then put $g=f_{1}+f_{3} f_{4}$. We have $\|g\| \leqq\left(1+4 M_{1}\right)\|f\|$ and $\| f-$ $g\left\|_{s} \leqq \varepsilon\right\| f \|\left(2+3 M_{1}\right)$.

So with $\varepsilon=1 /\left(4+6 M_{1}\right)$ we have what we want.

Finally I want to thank Dr. A. M. Davie for some very helpful correspondence which gave our results considerably greater generality.

\section{REFERENCES}

1. A. M. Davie, Bounded limits of analytic functions, (to appear).

2. T. W. Gamelin, Uniform Algebras, Prentice Hall, Englewood Cliffs. N. J. 1969.

3. K. Hoffmann, Banach Spaces of Analytic Functions, Prentice Hall, Englewood Cliffs. N. J. 1962.

4. J. Rainwater, A remark on regular Banach algebras, Proc. Amer. Math. Soc., 18 (1967), 255-256.

5. E. L. Stout, Two theorems concerning functions holomorphic in multiply connected domains, B. A. M. S., 69 (1963), 527-530.

6. A. Stray, Approximation and Interpolation. (to appear in Pacific J. Math.).

Received April 23, 1971.

UNIVERSITY OF OSLO 



\section{PACIFIC JOURNAL OF MATHEMATICS}

\section{EDITORS}

\author{
H. SAMELSON \\ Stanford University \\ Stanford, California 94305 \\ C. R. HOBBY \\ University of Washington \\ Seattle, Washington 98105
}

\section{J. DuGundJI}

Department of Mathematics University of Southern California Los Angeles, California 90007

RICHARD ARENS

University of California

Los Angeles, California 90024

\section{ASSOCIATE EDITORS}
E. F. BECKENBACH
B. H. NeumanN
F. WOLF
K. YOSHIDA

\section{SUPPORTING INSTITUTIONS}

\author{
UNIVERSITY OF BRITISH COLUMBIA \\ CALIFORNIA INSTITUTE OF TECHNOLOGY \\ UNIVERSITY OF CALIFORNIA \\ MONTANA STATE UNIVERSITY \\ UNIVERSITY OF NEVADA \\ NEW MEXICO STATE UNIVERSITY \\ OREGON STATE UNIVERSITY \\ UNIVERSITY OF OREGON \\ OSAKA UNIVERSITY
}

\author{
UNIVERSITY OF SOUTHERN CALIFORNIA \\ STANFORD UNIVERSITY \\ UNIVERSITY OF TOKYO \\ UNIVERSITY OF UTAH \\ WASHINGTON STATE UNIVERSITY \\ UNIVERSITY OF WASHINGTON \\ AMERICAN MATHEMATICAL SOCIETY \\ NAVAL WEAPONS CENTER
}

The Supporting Institutions listed above contribute to the cost of publication of this Journal, but they are not owners or publishers and have no responsibility for its content or policies.

Mathematical papers intended for publication in the Pacific Journal of Mathematics should be in typed form or offset-reproduced, (not dittoed), double spaced with large margins. Underline Greek letters in red, German in green, and script in blue. The first paragraph or two must be capable of being used separately as a synopsis of the entire paper. The editorial "we" must not be used in the synopsis, and items of the bibliography should not be cited there unless absolutely necessary, in which case they must be identified by author and Journal, rather than by item number. Manuscripts, in duplicate if possible, may be sent to any one of the four editors. Please classify according to the scheme of Math. Rev. Index to Vol. 39. All other communications to the editors should be addressed to the managing editor, Richard Arens, University of California, Los Angeles, California, 90024.

50 reprints are provided free for each article; additional copies may be obtained at cost in multiples of 50 .

The Pacific Journal of Mathematics is published monthly. Effective with Volume 16 the price per volume (3 numbers) is $\$ 8.00$; single issues, $\$ 3.00$. Special price for current issues to individual faculty members of supporting institutions and to individual members of the American Mathematical Society: $\$ 4.00$ per volume; single issues $\$ 1.50$. Back numbers are available.

Subscriptions, orders for back numbers, and changes of address should be sent to Pacific Journal of Mathematics, 103 Highland Boulevard, Berkeley, California, 94708.

PUBLISHED BY PACIFIC JOURNAL OF MATHEMATICS, A NON-PROFIT CORPORATION

Printed at Kokusai Bunken Insatsusha (International Academic Printing Co., Ltd.), 270, 3-chome Totsuka-cho, Shinjuku-ku, Tokyo 160, Japan. 


\section{Pacific Journal of Mathematics}

\section{Vol. 42, No. $2 \quad$ February, 1972}

Stephen Richard Bernfeld, The extendability of solutions of perturbed scalar differential equations ................................. 277

James Edwin Brink, Inequalities involving $f_{-} p$ and $f^{(n)}{ }_{q}$ for $f$ with $n$

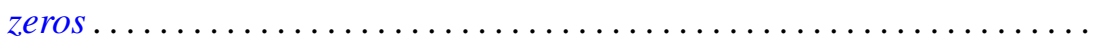

Orrin Frink and Robert S. Smith, On the distributivity of the lattice of filters of a groupoid

Donald Goldsmith, On the density of certain cohesive basic sequences .... 323

Charles Lemuel Hagopian, Planar images of decomposable continua . . . . . 329

W. N. Hudson, A decomposition theorem for biadditive processes ........ 333

W. N. Hudson, Continuity of sample functions of biadditive processes......

Masako Izumi and Shin-ichi Izumi, Integrability of trigonometric series.

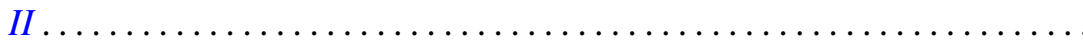

H. M. Ko, Fixed point theorems for point-to-set mappings and the set of

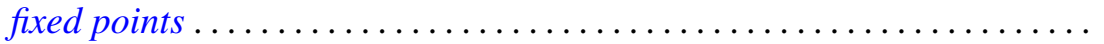

Gregers Louis Krabbe, An algebra of generalized functions on an open interval: two-sided operational calculus ...

Thomas Latimer Kriete, III, Complete non-selfadjointness of almost selfadjoint operators.................................

Shiva Narain Lal and Siya Ram, On the absolute Hausdorff summability of a Fourier series .

Ronald Leslie Lipsman, Representation theory of almost connected groups...

James R. McLaughlin, Integrated orthonormal series.... . .

H. Minc, On permanents of circulants.

Akihiro Okuyama, On a generalization of $\Sigma$-spaces.....

Norberto Salinas, Invariant subspaces and operators of class $(S)$

James D. Stafney, The spectrum of certain lower triangular matrices as operators on the $l_{p}$ spaces .......................

Arne Stray, Interpolation by analytic functions

$\mathrm{Li} \mathrm{Pi} \mathrm{Su}$, Rings of analytic functions on any subset of the complex plane.

R. J. Tondra, A property of manifolds compactly equivalent to compact manifolds.... 